\section{Glioma research: Early detection of a downward trend in publication productivity?}

\author{
Michael A. Meyer \\ Department of Neurology, Guthrie \\ Clinic, Sayre PA, USA
}

\begin{abstract}
Global publication productivity for brain tumors was examined on a annual basis and compared to other neurologic disorders including stroke, epilepsy and Alzheimer's disease. An early downward trend is suggested for 2016; possible links to fluctuations in funding is discussed.
\end{abstract}

\section{Editorial}

As Editor for the journal, I use the PubMed publications by year plotter to understand emerging trends in Neuroscience. With cutbacks in federal funding for medical research, I have been concerned that Neuroscience research productivity could drop and scientific advances will be hindered; critical areas of medicine that deal diseases with high mortality rates may suffer, such as Neuro-Oncology.

To explore this concern further, the timeline charting function of publications by year provided at Pubmed.gov was used to investigate whether the if there were any significant trends in glioma related publications on an annual basis relative to other major areas of Neurology such as stroke, epilepsy, and Alzheimer's disease. The PubMed data base of the National Library of Medicine was therefore searched for all articles with the primary search term glioma (without quotation marks). The annual number of publications appearing in the literature were reviewed by an automatically generated graph under results by year with 1870 being the first data point at 2 publications with a peak occurring in 2015 at 4574 . Data on annual funding to the National Cancer Institute (NCI) was graphed from 2008 through 2016 to analyze temporal trends in relation to publication productivity. For 2014, there were 4356 publications on glioma that appeared to be on ever rising trend and growing expansion with 4574 publications for the following year of 2015 . However, for the first time ever, a downward trend in publication productivity has now been noticed here for gliomas where the annual number dropped to 4104 (Figure
1; new updated numbers sampled in 2018 since the preparation of the figure still show the drop at 4299 for 2016; still lower at 4099 for 2017). This stands in contrast to other areas of Neurology where ever increasing numbers of papers are generated for the fields of Stroke, Epilepsy and Alzheimer's (Figure 1). In further confirmation of the findings, using the search terms brain neoplasm (without quotes) identified a steady growth in paper publication that peaked in 2015 at 6,792 with a first time trend downwards at 5,913 for 2016. Using the more narrow and restricted search terms of low grade glioma there were 167 publications for 2015 followed by 180 papers for 2016. For high grade glioma, there were 238 papers published in 2015 followed by 250 in 2016.

The data represents a potentially serious concern regarding a dip in productivity that may be multi-factorial with causes that include but are not limited to underfunding of brain tumor research. There may be technical explanations that relate to the search term, as the smaller volume and more restricted topic of glioblastoma had 2538 publications in 2015 that rose slightly to 2613 in 2016 but was higher for 2017 at 3128 .

It is unclear if this projected decline in overall glioma research productivity is an isolated trend or applies to other neoplasms. One possible explanation might be that interest in low grade glioma research has markedly declined for reasons of an unclear or unknown nature. Alternate considerations include a pervasive global drop in cancer research productivity or perhaps represents a regional drop off in cancer research productivity in certain parts of the world and affects studies on many types of cancer. Preliminary review suggests this not the case, as annual lung cancer publications grew globally from 9372 in year 2015 to 9894 in 2016. For breast cancer, total annual publications were 15,114 in 2015 that rose to 15,441 in 2016.

Trends in brain tumor research have been reviewed previously by Pope and Itagaki in 2010 where they studied publication trends on the subject between 1996 to 2007, encompassing 19,003 journal articles. ${ }^{1}$ They found the US to be the dominant source of the articles at $33 \%$ of the total; overall departmental source of the studies was most frequent for Neurosurgery which accounted for $26 \%$ of the total. The investigators noted that European government funding of brain tumor research was only $12 \%$ of that spent by NIH in 2005 (also, for brain research in general, US funding per capita is known to be 5 times higher in the US than Europe). ${ }^{2}$
Correspondence: Michael A. Meyer, Department of Neurology, Guthrie Clinic, One Guthrie Square, Sayre, Pennsylvania, USA. E-mail: michaelandrewmeyer@gmail.com

Key words: glioma publication productivity funding brain neoplasm.

Conflict of interest: the author declares no potential conflict of interest.

Funding: none

Received for publication: 4 January 2018. Accepted for publication: 4 January 2018.

This work is licensed under a Creative Commons Attribution NonCommercial 4.0 License (CC BY-NC 4.0).

(C) Copyright M.A. Meyer, 2018

Licensee PAGEPress, Italy

Neurology International 2018; 10:7562

doi:10.4081/ni.2018.7562

Approximately $32 \%$ of all papers from the US acknowledged support from the National Institute of Health (NIH). The investigators noted a $16 \%$ drop in annual NIH funding for brain tumor research in 2005 that may have correlated with what can be estimated to be a $10 \%$ drop in annual brain tumor publications from the US in 2007, further confirming the suspected downstream delayed effect on productivity that only first becomes apparent two to three years afterwards.

It is most likely that the decline in funding and increase in competition for scarce funds accounts for the downturn in productivity. As shown in Figure 2, the annual funding for NCI has fluctuated over the past few years and significantly dropped in 2013. ${ }^{3}$ As the time span from grant decision to the completion of the research with final publication of the results may be as long as 3 to 4 years, it is possible that the potential future negative impact from the 2013 drop in total NCI funding does not become apparent until 2016 and beyond; time to publication for completed clinical trials alone is on average 21 months. ${ }^{4}$ In 2013, when the drop in annual NCI funding occurred, brain \& CNS projects funded by NCI remained fairly stable at 176.8 million of that year alone, representing $3.69 \%$ of the total NCI budget (2010: 156.8 million, 2011: 172.6 million, 2012: 177.5 million, 2014: 180.4 million).

NIH funding for brain cancer increased from 280 million in 2013 to 310 million in 2016; the projected end of year expenditure of 335 million but will unfortu- 

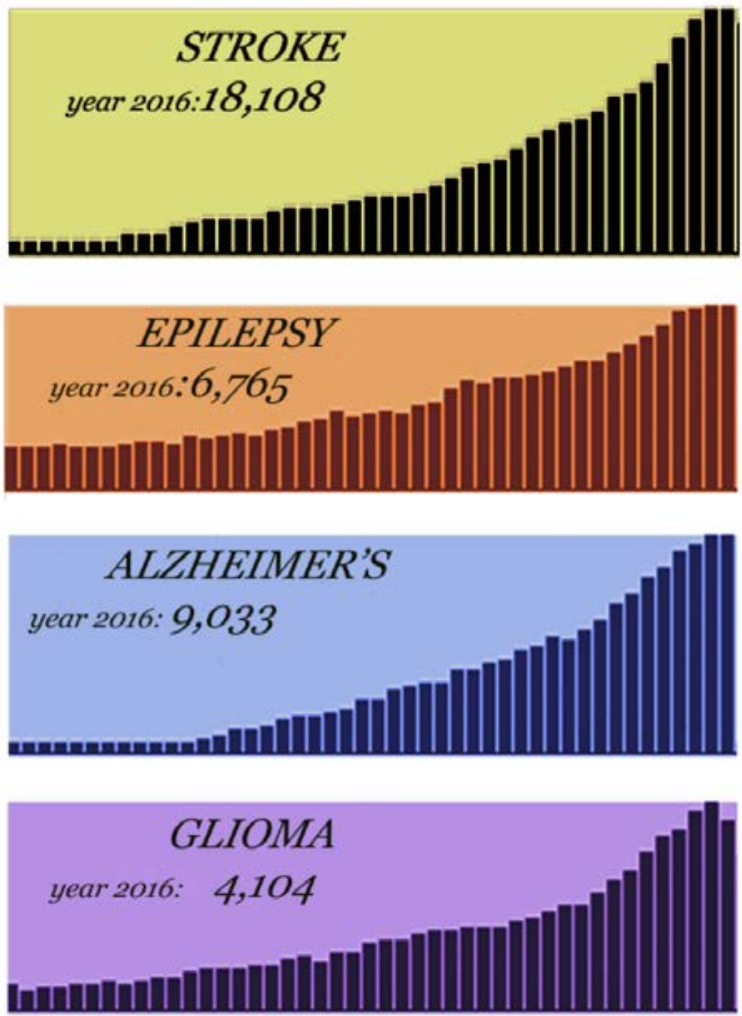

Figure 1. Bar graph for relative growth in annual publication rates for stroke, epilepsy, Alzheimer's disease, and glioma (last year of data entry for all of the graphs is 2016).

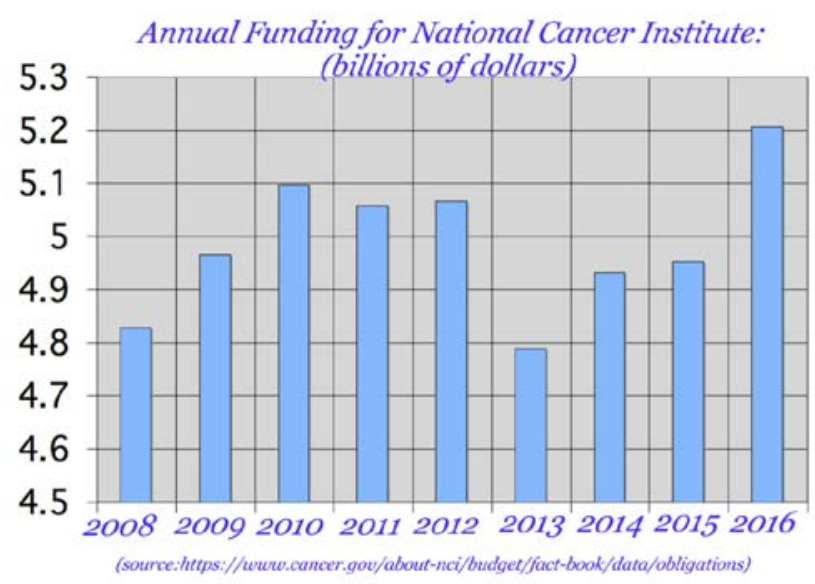

Figure 2. Annual funding for the National Cancer Institute (NCI) from 2008 to 2016 in billions of dollars. nately be reduced by $22 \%$ for the coming year of 2018 to only 260 million dollars to investigate a cure for this devastating disease that annually claims the lives of 16,618 US citizens annually $(0.1 \%$ of the population. 5,6 Similarly, overall cancer funding will drop by $22 \%$ from 6.032 billion in 2017 to 4.696 billion in 2018 (cancer claims the lives of 652,672 US citizens annually, equivalent to $8.7 \%$ of the population). Unfortunately, this cut in funding will likely slow the growth about how to control the growth of brain tumors and cancer in general, and likely drop publication productivity within the next 3 to 4 years.

The analysis presented here may have a number of limitations, including but not limited to technical errors with categorization of articles by topic within PubMed. As gliomas represent a significant unsolved problem, the apparent decline in total research productivity for gliomas is hopefully only a short lived anomaly but still is of concern that requires further attention by $\mathrm{NCI}$ and $\mathrm{NIH}$

\section{References}

1. Pope WB, Itagaki MW. Characterizing brain tumor research: the role of the National Institutes of Health. AJNR Am J Neuroradiol 2010;31:605-9.

2. Jager M, Lekander I, Sobocki P et al. Resource allocation to brain research in Switzerland Swiss Med Weekly
2008;138:335-9.

3. National Cancer Institute Budget. Available from: https://www.cancer.gov/about-nci/budget/fact-book/data/obligations

4. Ross JS, Mocanu M, Lampropulos JF, et al. Time to publication among completed clinical trials. JAMA Intern Med 2013;173:825-8.

5. NIH. NIH funding for brain tumors by individual funded project from 2011 onwards. Available from: https://report.nih.gov/categorical_spending project listing.aspx?FY=2011\&A $\mathrm{RRA}=\mathrm{N} \& \mathrm{DC} \overline{\mathrm{C}}=\mathrm{Brain} \% 20 \mathrm{Cancer}$

6. NIH. NIH budget by disease category from 2013 onwards. Available from: https://report.nih.gov/categorical_spending.aspx 